\title{
Physical Fitness across 11- to 17-Year-0ld Adolescents: A Cross-Sectional Study in 2267 Austrian Middle- and High-School Students
}

\author{
Klaus Greier ${ }^{1,2}$, Clemens Drenowatz ${ }^{3}$, Gerhard Ruedl ${ }^{1}$, Werner Kirschner ${ }^{1}$, \\ Peter Mitmannsgruber ${ }^{4}$, Carla Greier ${ }^{1}$ \\ ${ }^{1}$ Department of Sport Science, University Innsbruck, Innsbruck, Austria \\ ${ }^{2}$ Division of Physical Education, Private University of Education (KPH-ES), Stams, Austria \\ ${ }^{3}$ Division of Physical Education, University of Education (PHOOE), Linz, Austria \\ ${ }^{4}$ Division of Physical Education, University of Education (KPHVIE), Vienna/Krems, Austria \\ Email: *nikolaus.greier@kph-es.at
}

How to cite this paper: Greier, K., Drenowatz, C., Ruedl, G., Kirschner, W., Mitmannsgruber, P., \& Greier, C. (2019). Physical Fitness across 11- to 17-Year-Old Adolescents: A Cross-Sectional Study in 2267 Austrian Middle- and High-School Students. Advances in Physical Education, 9, 258-269.

https://doi.org/10.4236/ape.2019.94018

Received: September 27, 2019

Accepted: November 1, 2019

Published: November 4, 2019

Copyright $\odot 2019$ by author(s) and Scientific Research Publishing Inc. This work is licensed under the Creative Commons Attribution International License (CC BY 4.0).

http://creativecommons.org/licenses/by/4.0/

\begin{abstract}
Puberty is a critical period in the development of physical fitness. The purpose of this study, therefore, was to examine the development of various components of physical fitness in Austrian adolescents between 11 and 17 years of age. A total of 2267 (51\% male) adolescents from 18 secondary schools in Western Austria provided valid data. Following anthropometric measurements, participants performed the German motor test, which consists of 8 test items that assess speed, power, strength, endurance, agility, balance, and flexibility. Differences in physical fitness by age and sex were examined via a 2 by 7 MANOVA. In general, fitness improved between the ages 11 and 13 years in boys and girls. After the age of 13, physical fitness remained relatively stable in girls, while there was a continuous increase in physical fitness in boys, except for flexibility, which remained stable. Accordingly, boys performed better than girls, except for flexibility, which was better in girls. No sex difference occurred for balance. Biological changes (e.g. changes in sex hormones, body composition), contribute to significant gains in strength and endurance throughout adolescence, particularly in boys. In girls, increases in physical fitness were less pronounced and were generally limited after the age of 13 . This may also reflect behavioral changes and emphasizes the importance of continued promotion of physical activity and sports, particularly in girls.
\end{abstract}

\section{Keywords}

Motor Development, Sports Performance, Puberty, Youth, Strength, Power, Endurance, Speed, Agility, Flexibility, Balance 


\section{Introduction}

Physical activity (PA) and physical fitness are key components in the development and well-being of children and adolescents (Kettner et al., 2012). While PA is defined as any bodily movement as a result of muscular activity, physical fitness refers to the ability to perform activities of daily living without undue fatigue (Caspersen, Powell, \& Christenson, 1985). This also highlights the importance of physical fitness for the promotion of an active lifestyle. Further, the development of physical fitness is a critical component in human ontogenesis, along with the development of cognitive and social abilities, and has received considerable attention in the exercise science community (Bös \& Ulmer, 2003). Considerable changes in the social and built environment, however, contributed to an increased sedentary lifestyle in children and adolescents (Owen, Healy, Matthews, \& Dunstan, 2010; Reilly et al., 2004; Strong et al., 2005), which also affects physical fitness (Tomkinson, Léger, Olds, \& Cazorla, 2003).

Due to significant changes in body composition, hormonal status and social interactions, puberty appears to be a critical period for the development of physical fitness. Considerable improvements in various components of physical fitness are observed between 11 and 15 years, with more pronounced gains in strength and endurance in boys compared to girls (Baxter-Jones, 2001; Meinel \& Schnabel, 2014; Weineck, 2007). Other behaviors that emerge during adolescence (e.g. alcohol consumption, smoking) along with a reduction in PA, on the other hand, may impair physical fitness (Béghin et al., 2019; Coelho-E-Silva et al., 2013; Cumming, Standage, Gillison, \& Malina, 2008; Malina, Bouchard, \& Bar-Or, 2004). Poor physical fitness may further reduce interest in PA and sports (Dumith, Gigante, Domingues, \& Kohl, 2011; Weineck, 2007) and contribute to a vicious cycle of low PA and poor physical fitness. The HBSC (Health Behavior of School-aged Children) study, for example, showed a reduction in the prevalence of youth meeting current PA guidelines from roughly $25 \%$ at the age of 11 to only $16 \%$ at the age of 15 (WHO, 2008). Particularly in girls, previous research also showed a reduction or stagnation in physical fitness (Albrecht et al., 2016; Kimm et al., 2002; Owen et al., 2010; Pate, Wang, Dowda, Farrell, \& O'Neill, 2006). Strength and endurance performance of 15- to 18-year-old girls, for example, has been similar to that of girls between 12 and 13 years of age (Müller, Fastenbauer, \& Redl, 2008; Pate et al., 2006).

In order to enhance the understanding of the development of physical fitness in adolescents, the present study examined differences in various components of physical fitness in Austrian adolescents between 11 and 17 years of age. It was hypothesized that performance increases with increasing age but that the improvement in physical fitness would be less pronounced in girls compared to boys.

\section{Methods}

A total of 20 secondary schools within the federal state of Tyrol (Western Aus- 
tria) were randomly selected for participation. Two schools declined to participate due to organizational reasons, resulting in a final sample of 18 schools with more than 2200 students between 11 and 17 years of age. Parents received written information about the study via the participating schools and provided written informed consent. Participants provided oral consent at the time of data collection. All study procedures were approved by the Institutional Review Board of the University of Innsbruck and the school boards of the participating schools.

Data collection occurred during the school-year 2017/18 during regular school time in the gymnasium of the participating schools. Body weight $(\mathrm{kg})$ and height $(\mathrm{cm})$ were measured by trained technicians with participants wearing gym clothes and being barefoot. Specifically, body weight was measured to the nearest $0.1 \mathrm{~kg}$ with an electronic scale (SECA ${ }^{\circledR}$ 803, Hamburg, Germany). Height was measured to the nearest $0.1 \mathrm{~cm}$ via a portable stadiometer $\left(\mathrm{SECA}^{\circledR} 217\right.$, Hamburg, Germany). Subsequently, body mass index (BMI) was calculated $\left(\mathrm{kg} / \mathrm{m}^{2}\right)$ and converted to BMI percentiles (BMIPCT) using German reference values (Kromeyer-Hauschild et al., 2001). BMIPCT above the $90^{\text {th }}$ percentile was considered overweight/obese, while participants with BMIPCT below the $10^{\text {th }}$ percentile were considered underweight.

Motor competence was assessed by the German Motor Test (DMT 6-18), which has been shown to provide valid and reliable results for children and adolescents between 6 and 18 years of age (Bös et al., 2009). The DMT 6-18 consists of 8 test items that examine speed, agility, power, strength, balance, flexibility and endurance. Specifically, it consists of a $20 \mathrm{~m}$ sprint, sideways jumping, standing long-jump, push ups, sit ups, backwards balance, stand-and-reach, 6-minute run. Following anthropometric measurements, participants completed all tests during a single test session after a standardized 5-minute warm-up. The testing battery started with the $20 \mathrm{~m}$ sprint and ended with the 6-minute run. All other tests were performed at random order in between.

Statistical Analysis. Descriptive statistics were calculated; interval scaled data is shown as mean with standard deviation, while frequencies are shown for ordinal and nominal data. A 2 (sex) by 7 (age) multivariate analysis of variance (MANOVA) was used to examine differences across the specific test items by sex and age. In case of significant interaction effects, ANOVA was used to determine differences in motor competence across the 7 age groups for boys and girls separately. The statistical analysis was performed using SPSS 24.0 with a significance level set at $p \leq 0.05$ and Bonferroni adjustment for multiple comparisons.

\section{Results}

A total of 2267 middle- and high-school students (51.1\% boys) with an average age of $13.5 \pm 2.0$ years (girls: $13.7 \pm 2.1$ years; boys: $13.3 \pm 1.9$ years) provided valid data. Of the total sample, $21.8 \%$ were considered overweight/obese while $5.8 \%$ were considered underweight. There was no difference in weight status by age or sex. Anthropometric data by age group for the total sample and separately for boys and girls are shown in Table 1 . The results indicate a continuous linear 
Table 1. Anthropometric characteristics by age and sex. Values are Mean \pm SD.

\begin{tabular}{|c|c|c|c|c|c|c|c|c|}
\hline & & $\begin{array}{c}11 \text { years } \\
(\mathrm{N}=456)\end{array}$ & $\begin{array}{c}12 \text { years } \\
(\mathrm{N}=479)\end{array}$ & $\begin{array}{c}13 \text { years } \\
(\mathrm{N}=309)\end{array}$ & $\begin{array}{c}14 \text { years } \\
(\mathrm{N}=318)\end{array}$ & $\begin{array}{c}15 \text { years } \\
(\mathrm{N}=223)\end{array}$ & $\begin{array}{c}16 \text { years } \\
(\mathrm{N}=195)\end{array}$ & $\begin{array}{c}17 \text { years } \\
(\mathrm{N}=287)\end{array}$ \\
\hline \multirow{3}{*}{$\begin{array}{c}\text { Total } \\
(\mathrm{N}=2267)\end{array}$} & Height $(\mathrm{cm})$ & $149.6 \pm 8.8$ & $157.2 \pm 8.1$ & $162.4 \pm 8.5$ & $166.1 \pm 8.4$ & $169.4 \pm 8.3$ & $169.9 \pm 8.7$ & $170.6 \pm 9.5$ \\
\hline & Weight $(\mathrm{cm})$ & $43.8 \pm 12.0$ & $50.1 \pm 13.0$ & $55.3 \pm 13.5$ & $58.8 \pm 12.4$ & $62.3 \pm 13.2$ & $63.8 \pm 14.1$ & $66.2 \pm 12.8$ \\
\hline & BMI percentile & $59.8 \pm 31.2$ & $60.6 \pm 30.5$ & $62.6 \pm 28.7$ & $61.0 \pm 27.9$ & $58.5 \pm 27.5$ & $53.4 \pm 28.7$ & $55.3 \pm 30.1$ \\
\hline \multirow{3}{*}{$\begin{array}{c}\text { Girls } \\
(\mathrm{N}=1109)\end{array}$} & Height $(\mathrm{cm})$ & $150.0 \pm 8.0$ & $156.9 \pm 6.6$ & $160.9 \pm 6.3$ & $162.7 \pm 6.1$ & $165.1 \pm 6.2$ & $164.8 \pm 6.6$ & $164.2 \pm 5.9$ \\
\hline & Weight $(\mathrm{cm})$ & $44.2 \pm 12.3$ & $50.1 \pm 12.2$ & $54.8 \pm 10.9$ & $57.0 \pm 11.2$ & $59.0 \pm 11.0$ & $60.2 \pm 12.9$ & $60.8 \pm 10.8$ \\
\hline & BMI percentile & $59.8 \pm 32.0$ & $60.6 \pm 30.9$ & $64.7 \pm 27.3$ & $61.1 \pm 27.7$ & $57.0 \pm 28.0$ & $51.5 \pm 28.9$ & $50.5 \pm 32.2$ \\
\hline \multirow{3}{*}{$\begin{array}{c}\text { Boys } \\
(\mathrm{N}=1158)\end{array}$} & Height $(\mathrm{cm})$ & $149.2 \pm 9.5$ & $157.4 \pm 9.0$ & $163.3 \pm 9.6$ & $169.7 \pm 8.9$ & $174.4 \pm 7.6$ & $177.2 \pm 5.7$ & $178.7 \pm 6.8$ \\
\hline & Weight $(\mathrm{cm})$ & $43.2 \pm 11.7$ & $50.0 \pm 13.5$ & $55.6 \pm 15.0$ & $60.8 \pm 13.4$ & $66.3 \pm 14.5$ & $68.9 \pm 14.2$ & $73.0 \pm 11.8$ \\
\hline & BMI percentile & $59.8 \pm 30.3$ & $60.6 \pm 30.3$ & $61.3 \pm 29.6$ & $61.0 \pm 28.3$ & $60.3 \pm 26.9$ & $56.0 \pm 28.5$ & $61.3 \pm 26.0$ \\
\hline
\end{tabular}

growth between 11 and 17 years of age with a slower growth rate after the age of 15. Weight change occurred in a similar pattern, which resulted in no significant differences in BMIPCT across age groups in boys. In girls, linear growth appears to slow around the age of 13 with a plateau after 15 years of age. Weight followed a similar pattern, resulting in only minor differences in BMIPCT across age groups.

Speed (20-m-Sprint). There was a significant sex by age interaction effect for sprint performance $(p<0.001)$. Even though boys and girls showed a significant improvement until the age of 13 , boys continued to improve their sprinting performance, while girls displayed a plateau. Accordingly, there was no significant difference in sprinting performance between the ages 13 and 17 in girls. 17-year-old boys, on the other hand, displayed significantly better sprinting performance compared to the age groups of 11 to 14 years $(p<0.013)$. Across the entire age range, boys displayed significantly better sprinting performance than girls (Figure 1).

Standing Long-Jump. There was a significant sex by age interaction effect ( $p<$ $0.001)$. In boys, performance improved significantly across age groups until the age of $15(p<0.005)$. In girls, the improvement was less pronounced and plateaued after the age of 15 . Nevertheless, standing-long jump performance of 17-year-old girls was significantly better compared to 11- or 12-year-old girls. Across the entire age range, boys displayed significantly better jumping performance than girls (Figure 2).

Push Ups. There was a significant age by sex interaction effect $(p=0.011)$. Both, boys and girls, showed a significant improvement from the age of 12 to 13 . After the age of 13, performance remained relatively constant in boys. Accordingly, 17-year-old boys performed a higher number of push ups compared 11and 12-year-old boys. In girls, there was a slight decline in push up performance after the age of 13, resulting in no significant differences between 17-year-old girls compared to the younger age groups. Across the entire sample, boys displayed significantly better performance than girls (Figure 3 ). 


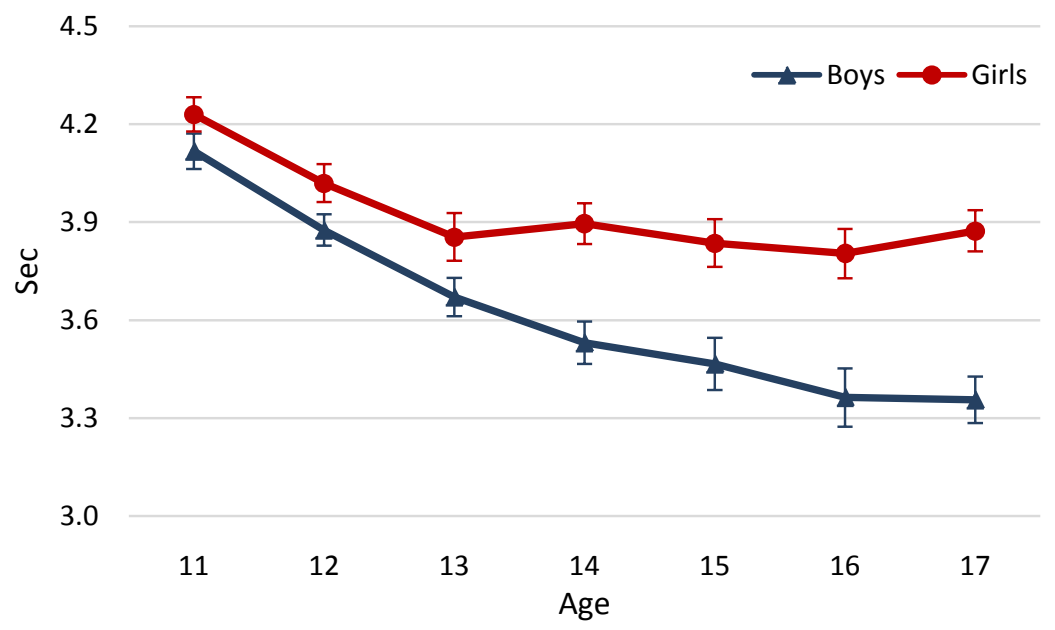

Figure 1. 20-m-Sprint performance by age and sex $(\mathrm{N}=2267)$. Values are mean with 95\% CI.

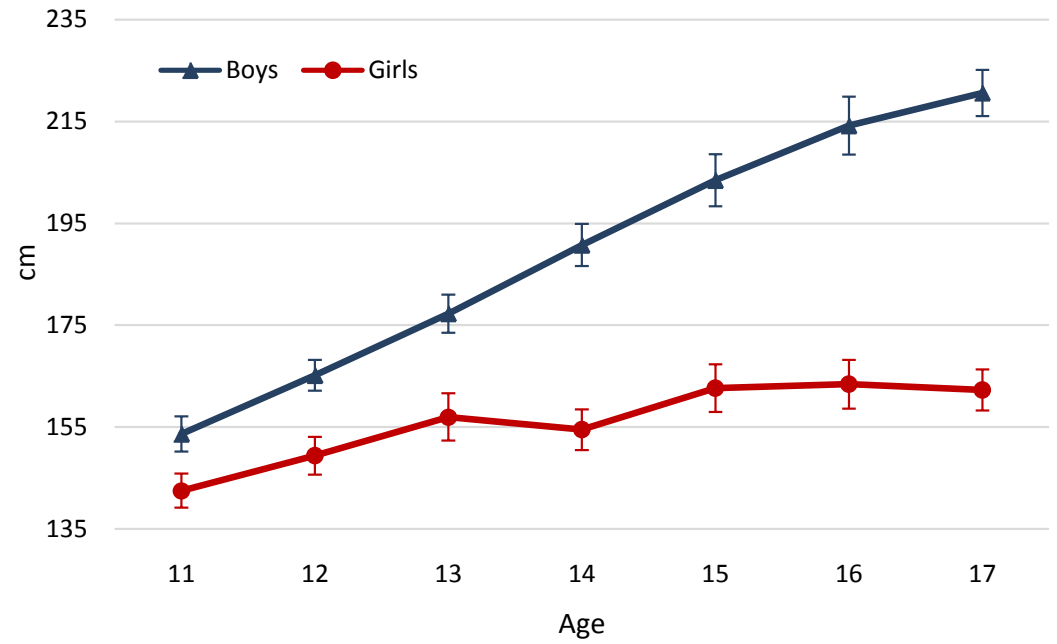

Figure 2. Standing long-jump performance by age and sex $(\mathrm{N}=2267)$. Values are mean with $95 \%$ CI.

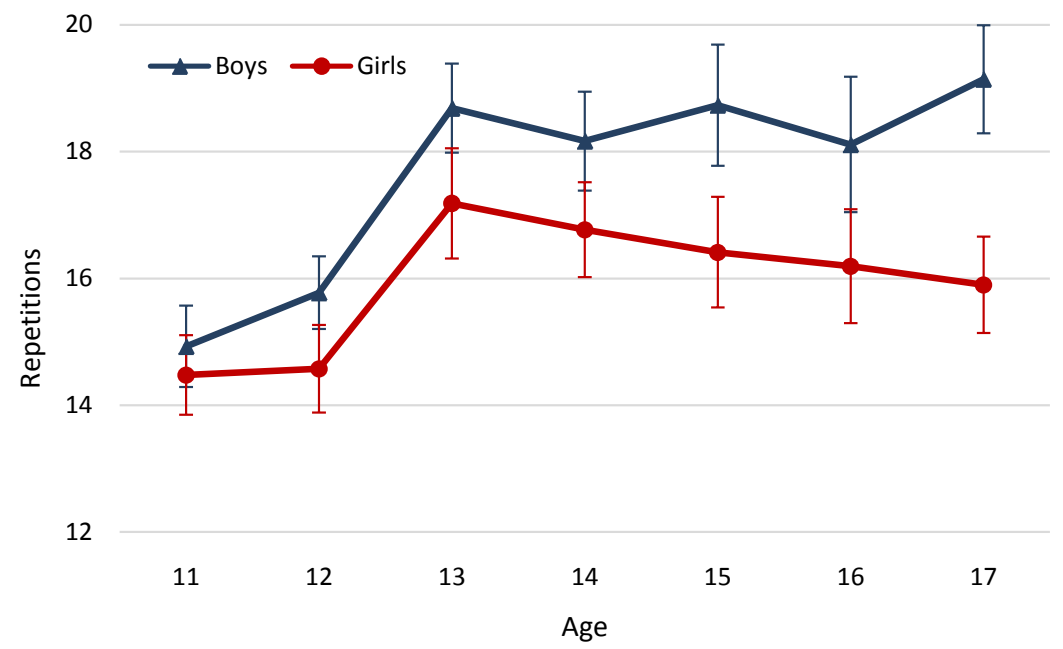

Figure 3. Push up performance by age and sex $(\mathrm{N}=2267)$. Values are mean with $95 \% \mathrm{CI}$. 
Sit Ups. There was a significant sex by age interaction effect on sit ups $(p<$ 0.001 ). In boys, the number of sit ups increased significantly for each age group between 11 and 13 years. After the age of 13, the improvement was less pronounced but 17-year-old boys performed significantly more sit ups than 11- to 14-year-old boys. In girls, improvement across age groups was less pronounced and remained relatively stable after the age of 13 . Due to a significant improvement from the age of 12 to 13,17-year-old girls performed a higher number of repetitions than girls at the age of 11 and 12. Across the entire age range, boys displayed significantly better performance than girls (Figure 4).

Endurance (6-min-Run). There was a significant sex by age interaction effect on endurance performance $(p<0.001)$. Girls displayed a significant improvement from 11 to 12 years of age $(p=0.014)$. After the age of 12 , endurance performance remained relatively stable with a gradual decline after the age of 15 . Nevertheless, 17-year-old girls displayed a significantly better 6-minute run performance than 11-year-old girls. In boys, there was a gradual improvement in endurance performance from the age of 11 to the age of 17 with a significant improvement between the ages 14 and 15. Accordingly, 17-year-old boys displayed a better 6-minute-run performance than 11 to 14 -year-old boys. Across the entire age range, endurance performance was significantly better in boys compared to girls (Figure 5).

Agility (Sideways Jumping). There was a significant sex by age interaction effect for sideways jumping $(p<0.001)$ even though, a significant improvement in agility was observed between 11 and 13 years of age in boys and girls $(p<0.001)$. After the age of 13, sideways jumping remained relatively stable in girls, while there was a small continued improvement in boys across older age groups. 17-year-old boys, therefore, displayed significantly better agility than boys between the age of 11 and 13 years $(p<0.007)$, while in girls the difference was only significant between the age of 17 and 11 as well as 12 years $(p<0.001)$. Across the entire sample, boys displayed better agility than girls, which became particularly pronounced at age groups 14 and older (Figure 6).

Flexibility (Stand and Reach Test). There was a significant sex by age interaction effect on flexibility $(p<0.001)$. Flexibility remained relatively constant in boys across the entire age range, while in girls there was an annual improvement in flexibility from the ages 11 to 13 . After the age of 13 flexibility remained relatively stable and 17-year-old girls displayed better flexibility compared to girls at the age of 11 and $12(p<0.001)$. The improvement in flexibility in early adolescent girls also contributed to a significantly better flexibility in girls compared to boys between 11 and 17 years of age (Figure 7).

Balance. There was no sex by age interaction effect on balance. Balance improved gradually with increasing age $(p<0.001)$ resulting in a better balance performance of 17-year-old boys compared to boys at the age of $11(p=0.009)$. In girls, 17-year-old adolescents displayed better balance ability compared to 11 and 12-year-old girls $(p=0.002)$. There was no sex difference for backwards balancing across 11- to 17-year-old adolescents (Figure 8). 


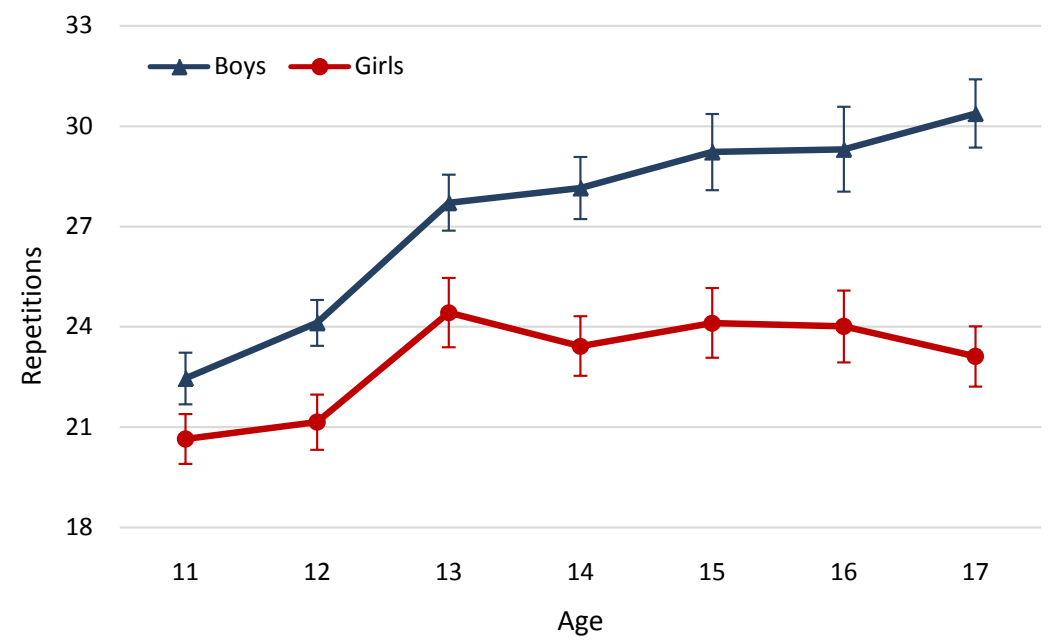

Figure 4. Sit up performance by age and sex $(\mathrm{N}=2267)$. Values are mean with $95 \% \mathrm{CI}$.

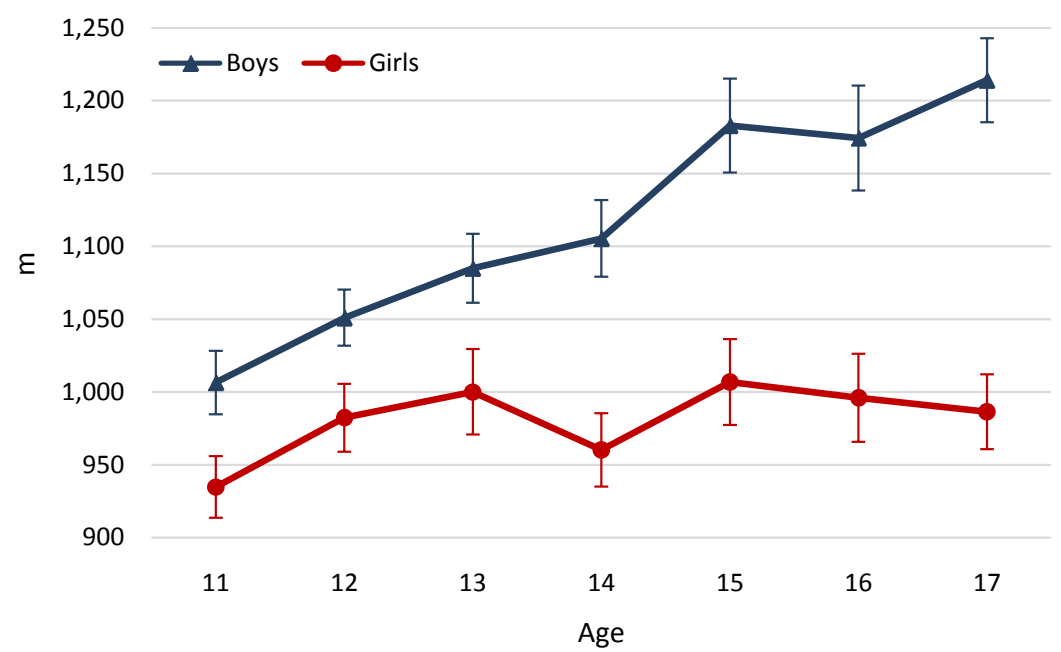

Figure 5. 6-Minute-Run performance by age and sex $(\mathrm{N}=2267)$. Values are mean with $95 \%$ CI.

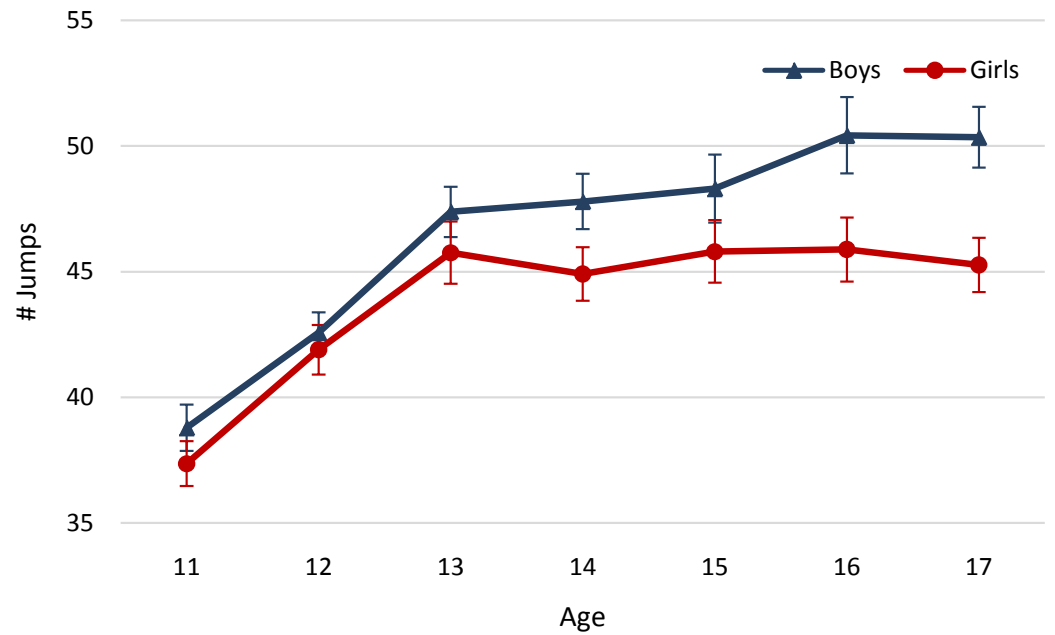

Figure 6. Sideways jumping performance by age and sex $(\mathrm{N}=2267)$. Values are mean with 95\% CI. 


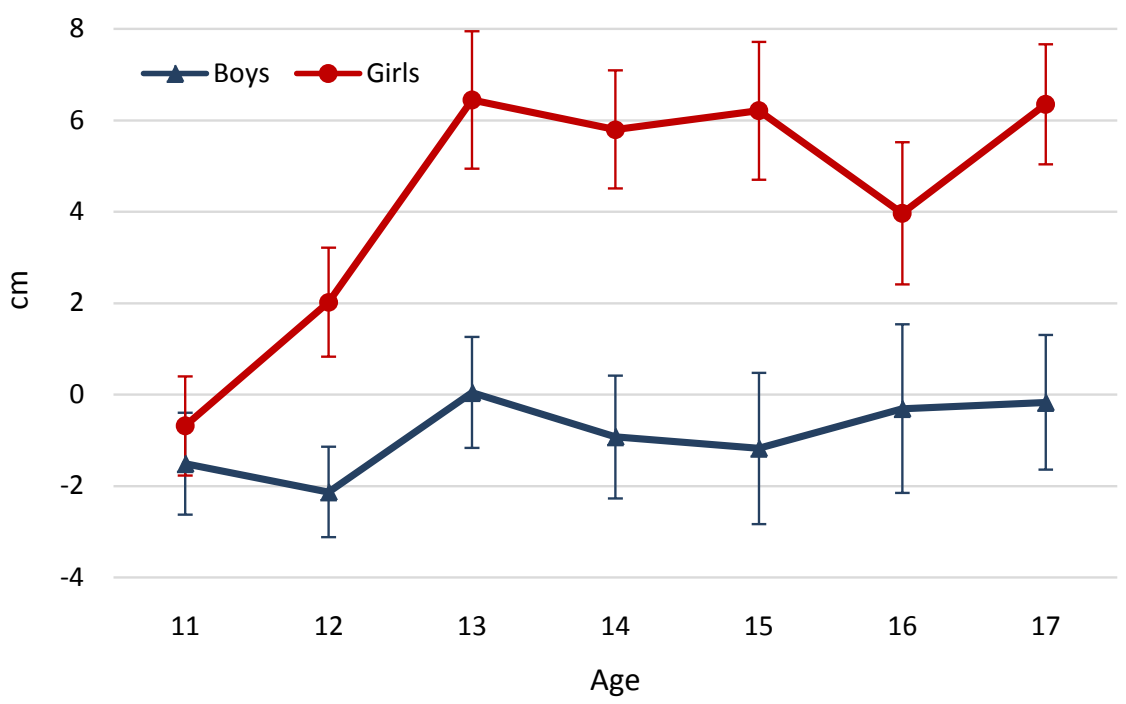

Figure 7. Flexibility by age and sex $(\mathrm{N}=2267)$. Values are mean with $95 \% \mathrm{CI}$.

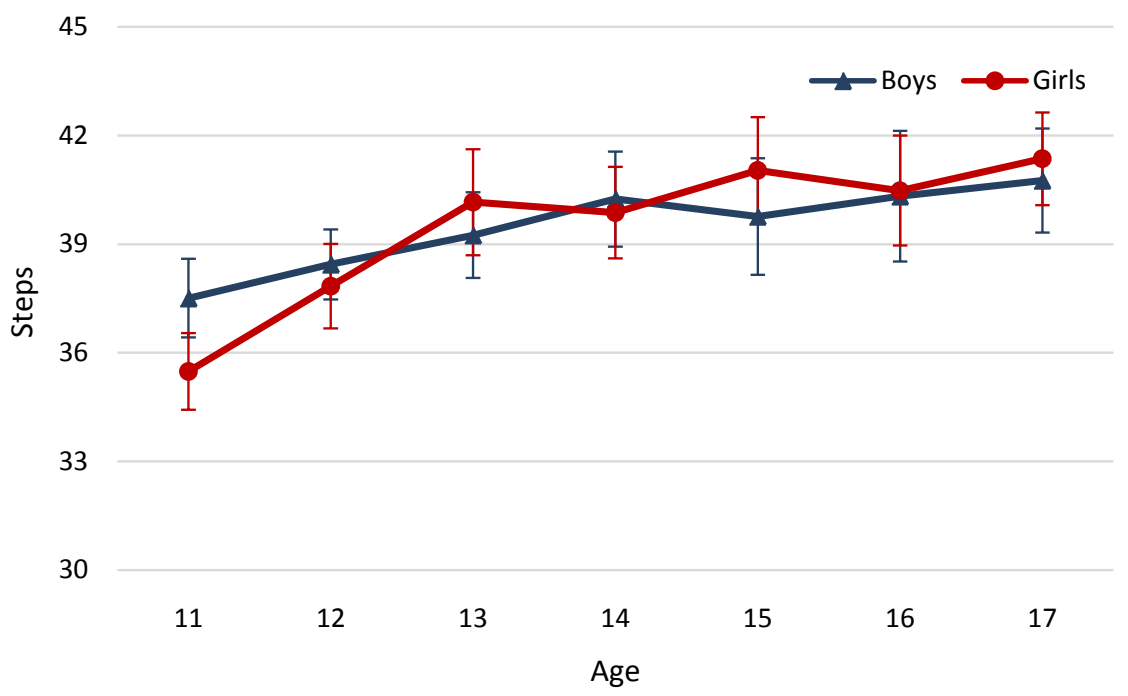

Figure 8. Backwards balance performance by age and sex $(\mathrm{N}=2267)$. Values are mean with $95 \%$ CI.

In summary, this study showed that boys generally display higher physical fitness than girls with the exception of flexibility. In addition, speed, muscular strength, endurance and agility were shown to increase with age and this increase was generally more pronounced in boys than in girls. In girls, improvements in physical fitness generally occurred only during early adolescence with a stagnation or even a decline following puberty, while the improvement in endurance and strength-related tasks continued throughout adolescents in boys.

\section{Discussion}

As has been shown in previous studies, the results of the present study show an improvement in physical fitness between 11 and 17 years of age (Albrecht et al., 2016; Fetz \& Kornexl, 1993; Weineck, 2007). Sex differences were already ap- 
parent at the age of 11 with better performance in boys compared to girls. These differences became even more pronounced after the age of 13 , which can be attributed to hormonal changes (e.g. testosterone) that contribute to improvements in strength, speed and endurance (Malina et al., 2004; Meinel \& Schnabel, 2014).

speed. There is considerable improvement in speed during adolescence. Sex differences are already apparent at 11 years of age and become more pronounced, particularly in tasks requiring strengths as well (e.g. sprint) (Meinel \& Schnabel, 2014). In boys, sprint performance improved almost linearly across the entire age range, while there was a stagnation in sprint performance after the age of 13 years in girls. This may be explained by the continuous increase in muscular strength in boys during puberty, which also affects sprint ability. In addition to biological changes behavioral changes, such as reductions in PA and engagement in activities that stimulate speed-related adaptations may further contribute to the observed stagnation in girls. These results are also in line with a previous study in Tyrolean adolescents (Fetz \& Kornexl, 1993).

Muscular strength. Muscular strength improved during adolescence in boys, while changes in strength-related tasks were limited in girls. Accordingly, sex differences in muscular strength increase between the ages 11 to 17 years.

Significant improvements in upper body strength, nevertheless, occurred predominantly during early adolescence in boys and girls. After the age of 13 , girls showed a decline in upper body strength at older ages, while performance remained relatively stable in boys. An increase in body weight may contribute to these results, which have been shown in previous studies (Fetz \& Kornexl, 1993; Müller et al., 2008).

Sex differences were even more pronounced for strength endurance and muscular power. Boys displayed a continuous increase in muscular power, while the increase in strength endurance was more pronounced during early adolescence with smaller changes after the age of 13. In girls, muscular power and strength endurance increased until the age of 13 and remained relatively stable afterwards. Similar results have been shown previously (Albrecht et al., 2016) and confirm the increasing discrepancies in muscular strength between boys and girls during adolescence.

Endurance. Already at the age of 11, there were significant sex differences in endurance capacity between boys and girls. Girls also displayed limited changes in endurance capacity after the age of 12 . The present results along with previous studies actually indicate a decline in endurance capacity after puberty in girls (Müller et al., 2008; Pate et al., 2006). In boys, on the other hand, endurance capacity increased throughout adolescence with a particularly pronounced increase between 14 and 15 years of age. Given the importance of endurance capacity regarding cardiovascular health (Houston et al., 2013), ensuring a sufficient endurance capacity during adolescence should be an important component in health promotion strategies.

Agility. As has been shown for muscular strength, agility increased significantly in boys and girls between 11 and 13 years of age. Subsequently, boys con- 
tinued to show improved performance in agility, even though to a lesser degree. In girls, agility, remained relatively stable after 13 years of age. Accordingly, sex differences in agility became more pronounced during late adolescence.

Flexibility and balance. Consistent with previous research, girls displayed better flexibility than boys during adolescence (Albrecht et al., 2016; Drenowatz \& Greier, 2019; Greier et al., 2019). Girls also displayed a significant improvement in flexibility between 11 and 13 years of age with limited changes afterwards. In boys, flexibility remained relatively stable across the entire age range. These sex differences have been attributed to a higher body fat percentage along with lower muscle mass in girls compared to boys (Weineck, 2007).

No sex differences were observed for balance. Age-related improvement in balance was also limited. Nevertheless, 17-year-old boys and girls performed significantly better on the balance task than their 11-year-old peers.

\section{Conclusion}

The present study showed that there is considerable variability in components of physical fitness during adolescence. Boys generally display higher physical fitness than girls with the exception of flexibility. In addition, speed, muscular strength, endurance and agility were shown to increase with age and this increase was generally more pronounced in boys than in girls. In girls, improvements in physical fitness generally occurred only during early adolescence with a stagnation or even a decline following puberty. Besides growth-related aspects (i.e. leg length), hormonal changes appear to be key contributors to alterations in physical fitness and put boys at an advantage over girls. These changes, however, may influence psychological and social development along with behavioral choices. Participation in organized sports, for example, has been shown to affect physical fitness, particularly during adolescence and boys have been shown to be more likely to participate in organized sports than girls (Drenowatz, Greier, Ruedl, \& Kopp, 2019; Greier, Kaiser, Hager, \& Scheu, 2015). Girls, therefore, may require special attention when it comes to promoting organized sports as this may help to reduce sex differences in physical fitness. It may also facilitate a continued improvement in physical fitness during late adolescence rather than a stagnation or decline following puberty. Given the importance of physical fitness on general health and well-being, continued engagement in various forms of PA that stimulate physical fitness is needed and should be promoted at home, in schools and through club sports.

\section{Conflicts of Interest}

The authors declare no conflicts of interest regarding the publication of this paper.

\section{References}

Albrecht, C., Hanssen-Doose, A., Bös, K., Schlenker, S., Schmidt, S. et al. (2016). Moto- 
rische Leistungsfähigkeit von Kindern und Jugendlichen in Deutschland. Sportwissenschaft, 46, 294-304. https://doi.org/10.1007/s12662-016-0421-4

Baxter-Jones, A. (2001). Endurance Training in Young Athletes. London, UK: Churchill Livingstone.

Béghin, L., Vanhelst, J., Drumez, E., Migueles, J. H., Androutsos, O. et al. (2019). Gender Influences Physical Activity Changes during Adolescence: The HELENA Study. Clinical Nutrition. (In Press) https://doi.org/10.1016/j.clnu.2018.12.027

Bös, K., \& Ulmer, J. (2003). Motor Development in Children. Monatsschrift Kinderheilkunde, 151, 14-21. https://doi.org/10.1007/s00112-002-0623-8

Bös, K., Schlenker, L., Büsch, D., Lämmle, L., Müller, H. et al. (2009). Deutscher Motorik-Test 6-18 (DMT6-18) [German Motor Abilities Test 6-18 (DMT6-18)]. Hamburg, Germany: Czwalina.

Caspersen, C. J., Powell, K. E., \& Christenson, G. M. (1985). Physical Activity, Exercise, and Physical Fitness: Definitions and Distinctions for Health-Related Research. Public Health Reports, 100, 126-131.

Coelho-E-Silva, M. J., Vaz Ronque, E. R., Cyrino, E. S., Fernandes, R. A., Valente-Dos-Santos, J. et al. (2013). Nutritional Status, Biological Maturation and Cardiorespiratory Fitness in Azorean Youth Aged 11-15 Years. BMC Public Health, 13, 495.

https://doi.org/10.1186/1471-2458-13-495

Cumming, S. P., Standage, M., Gillison, F., \& Malina, R. M. (2008). Sex Differences in Exercise Behavior during Adolescence: Is Biological Maturation a Confounding Factor? Journal of Adolescent Health, 42, 480-485.

https://doi.org/10.1016/j.jadohealth.2007.10.005

Drenowatz, C., \& Greier, K. (2019). Cross-Sectional and Longitudinal Association of Sports Participation, Media Consumption and Motor Competence in Youth. Scandinavian Journal of Medicine \& Science in Sports, 29, 854-861.

https://doi.org/10.1111/sms.13400

Drenowatz, C., Greier, K., Ruedl, G., \& Kopp, M. (2019). Association between Club Sports Participation and Physical Fitness across 6- to 14-Year-Old Austrian Youth. International Journal of Environmental Research and Public Health, 16, 3392.

https://doi.org/10.3390/ijerph16183392

Dumith, S. C., Gigante, D. P., Domingues, M. R., \& Kohl, H. W. (2011). Physical Activity Change during Adolescence: A Systematic Review and a Pooled Analysis. International Journal of Epidemiology, 40, 685-698. https://doi.org/10.1093/ije/dyq272

Fetz, F., \& Kornexl, E. (1993). Sportmotorische Tests. Praktsiche Anleitung zu sportmotorischen Tests in Schule und Verein (3 ed.). Vienna, Austria: ÖBV Pädagogischer Verlag.

Greier, K., Drenowatz, C., Ruedl, G., Kirschner, W., Lackner, C. et al. (2019). Motor Competence across 6- to 10-Year Old Children: A Cross-Sectional Study in 1811 Elementary School Students. Journal of Health Science \& Education, 3, 162.

Greier, K., Kaiser, S., Hager, A., \& Scheu, A. (2015). Einfluss ausgewählter Risikofaktoren auf die motorische Leistungsfähigkeit von 10-bis 11-jährigen Schulkindern. Bewegungstherapie und Gesundheitssport, 31, 69-75.

https://doi.org/10.1055/s-0035-1547419

Houston, E. L., Baker, J. S., Buchan, D. S., Stratton, G., Fairclough, S. J. et al. (2013). Cardiorespiratory Fitness Predicts Clustered Cardiometabolic Risk in 10-11.9-Year-Olds. European Journal of Pediatrics, 172, 913-918.

https://doi.org/10.1007/s00431-013-1973-Z

Kettner, S., Wirt, T., Fischbach, N., Kobel, S., Kesztyüs, D. et al. (2012). Necessity for 
physical activity promotion in German children. German Journal of Sports Medicine, 63, 94-101. https://doi.org/10.5960/dzsm.2012.016

Kimm, S. Y., Glynn, N. W., Kriska, A. M., Barton, B. A., Kronsberg, S. S. et al. (2002). Decline in Physical Activity in Black Girls and White Girls during Adolescence. The New England Journal of Medicine, 347, 709-715. https://doi.org/10.1056/NEJMoa003277

Kromeyer-Hauschild, K., Wabitsch, M., Kunze, D., Geller, F., Geiß, H. et al. (2001). Perzentile für den Body-mass-Index für das Kindes- und Jugendalter unter Heranziehung verschiedener deutscher Stichproben. Monatsschrift Kinderheilkunde, 149, 807-818. https://doi.org/10.1007/s001120170107

Malina, R. M., Bouchard, C., \& Bar-Or, O. (2004). Growth, Maturation, and Physical Activity (2nd ed.). Champaign, IL: Human Kinectics.

Meinel, K., \& Schnabel, G. (2014). Bewegungslehre-Sportmotorik(12 ed.). Aachen: Meyer \& Meyer Verlag.

Müller, E., Fastenbauer, V., \& Redl, S. (2008). Klug und Fit online-Bericht zur Erhebung der motorischen Leistungsfähigkeit 10-bis 14-jähriger österreichischer SchülerInnen. Ergebnisse und Folgerungen. Vienna, Austria: Bundesministerium für Unterricht, Kunst und Kultur.

Owen, N., Healy, G., Matthews, C., \& Dunstan, D. (2010). Too Much Sitting: The Population Health Science of Sedentary Behavior. Exercise and Sport Sciences Reviews, 38, 105-113. https://doi.org/10.1097/JES.0b013e3181e373a2

Pate, R. R., Wang, C. Y., Dowda, M., Farrell, S. W., \& O’Neill, J. R. (2006). Cardiorespiratory Fitness Levels among US Youth 12 to 19 Years of Age: Findings from the 1999-2002 National Health and Nutrition Examination Survey. Archives of Pediatrics and Adolescent Medicine, 160, 1005-1012.

Reilly, J. J., Jackson, D. M., Montgomery, C., Kelly, L. A., Slater, C. et al. (2004). Total Energy Expenditure and Physical Activity in Young Scottish Children: Mixed Longitudinal Study. The Lancet, 363, 211-212. https://doi.org/10.1016/S0140-6736(03)15331-7

Strong, W. B., Malina, R. M., Blimkie, C. J., Daniels, S. R., Dishman, R. K. et al. (2005). Evidence Based Physical Activity for School-Age Youth. The Journal of Pediatrics, 146, 732-737. https://doi.org/10.1016/j.jpeds.2005.01.055

Tomkinson, G. R., Léger, L. A., Olds, T. S., \& Cazorla, G. (2003). Secular Trends in the Performance of Children and Adolescents (1980-2000): An Analysis of 55 Studies of the 20m Shuttle Run Test in 11 Countries. Sports Medicine, 33, 285-300. https://doi.org/10.2165/00007256-200333040-00003

Weineck, J. (2007). Optimales Training. Leistungsphysiologische Trainingslehre unter besonderer Berücksichtigung des Kinder- und Jugendtrainings (15 ed.). Balingen, Germany: Spitta.

World Health Organization (2008). Inequalities in Young People's Health. HBSC International Report from the 2005/2006 Survey. Edinburgh, Scotland: WHO Press. 